\title{
Identification of SYT-SSX transcripts from synovial sarcomas using RT-multiplex PCR and capillary electrophoresis
}

\author{
John A Thorson, Helmut C Weigelin, Robert E Ruiz, Jennifer K Howard and David R Lucas \\ Department of Pathology, University of Michigan, Ann Arbor, MI, USA
}

\begin{abstract}
Synovial sarcomas are highly malignant tumors of soft tissue which are characterized by the $t(X ; 18)$ resulting in SYT-SSX fusion transcript production. Diagnosis of these tumors based on histology can be challenging, particularly when minimal biopsy specimens are presented to the pathologist. Demonstration by molecular methods of SYT-SSX transcripts is a useful adjunct for diagnosis in these situations. We have developed an assay, which combines one-step RT-multiplex PCR with capillary electrophoresis to detect and genotype the SYT-SSX transcripts from synovial sarcomas. Small amplicons from chimeric transcripts as well as GAPD transcripts are differentially labeled with fluorophores, allowing detection and size discrimination by capillary electrophoresis. In a study of $\mathbf{3 2}$ formalin-fixed soft tissue tumor specimens, the assay detected chimeric transcripts from $17 / 22(77 \%)$ synovial sarcomas. All five assay negative specimens yielded no intact RNA as evidenced by lack of a GAPD amplicon. Chimeric transcripts were not detected in 9/9 malignant peripheral nerve sheath tumors or $1 / 1$ epithelioid sarcoma. Representative amplicons were sequenced and confirmed the genotype results obtained by capillary electrophoresis. One-step RT-multiplex PCR combined with capillary electrophoresis is a rapid and accurate method for the detection and genotypic classification of SYT-SSX transcripts from fixed tissue specimens.
\end{abstract}

Modern Pathology (2006) 19, 641-647. doi:10.1038/modpathol.3800558; published online 17 March 2006

Keywords: synovial sarcoma; SYT-SSX; translocation; solid tumor; RT-PCR

Synovial sarcomas account for approximately 5$10 \%$ of all soft tissue sarcomas. They are aggressive, highly malignant tumors, typically developing around the large joints of the extremities, especially the knee and thigh. They occur most frequently in adolescents and young adults (annual incidence approximately 1 per million) and with equal frequency in males and females. The overall prognosis associated with these tumors is poor, with $25 \%$ of patients succumbing to their disease within 5 years of diagnosis in spite of aggressive treatment modalities. ${ }^{1}$ The name synovial sarcoma was applied to the tumors because they were initially believed to originate from synovium; however, the tumors typically display morphological and phenotypic characteristics of epithelial, not synovial, differentiation. The true cell of origin remains

Correspondence: Dr JA Thorson, MD, PhD, Department of Pathology, University of Michigan, 2910 Huron Parkway Suite C, Room 1103, Ann Arbor, MI 48105, USA.

E-mail: jathorso@umich.edu

Received 17 November 2005; accepted 23 December 2005; published online 17 March 2006 unknown, but it is currently believed that these tumors arise from a type of pluripotent stem cell. ${ }^{2}$

Histologically, synovial sarcomas are generally divided into two subtypes: biphasic and monophasic. Biphasic tumors contain both epithelial cells arranged in gland-like structures and spindle shaped cells, whereas monophasic tumors are composed of spindle cells only. Histologic diagnosis of synovial sarcoma can be challenging, particularly for the monophasic type, as they can closely resemble other spindle cell tumors.

The $\mathrm{t}(\mathrm{X} ; 18)$ translocation was first recognized as a hallmark of synovial sarcomas in the 1980s. ${ }^{3,4}$ This translocation has been shown to be present in over $95 \%$ of synovial sarcomas, regardless of histologic subtype. ${ }^{2}$ The molecular characterization of the breakpoints involved in the translocation identified novel genes, designated $S S X$ (at Xp11) and $S Y T$ (at 18q11). ${ }^{5}$ Protein products of both the $S Y T$ and $S S X$ genes appear to function as transcription regulatory factors, although their target genes are presently unknown. ${ }^{6}$ Subsequent work has shown that the breakpoint at Xp11 can alternatively involve one of at least three closely related members of an $S S X$ gene family, designated $S S X 1, S S X 2$, and $S S X 4 .^{7-9}$ 
The translocation breakpoints consistently occur in intron 10 of the SYT gene and intron 4 of the $S S X$ genes. ${ }^{6,10}$ Transcription of the resulting chimeric gene typically produces an in-frame transcript composed of exons 1-10 of the SYT gene fused to exons 5 and 6 of an SSX gene.

As a result of its high prevalence in synovial sarcomas, the $t(X ; 18)$ translocation and more specifically the resulting $S Y T-S S X$ fusion transcript, is a highly sensitive diagnostic marker for these tumors. Its specificity for synovial sarcoma has been shown to approach $100 \%$ in studies of morphologically similar sarcomas. ${ }^{11-13}$ The ratio of tumors harboring $S Y T-S S X 1$ fusions to those with SYT-SSX2 fusions is approximately $2: 1$, while tumors harboring the $S Y T-S S X 4$ fusion are extremely rare. Although the clinical significance of the alternate SYT-SSX fusion types is unclear, ${ }^{14-16}$ there is a strong correlation between biphasic tumor morphology and the presence of an SYT-SSX1 fusion. ${ }^{17}$

Demonstration by molecular methods of an $S Y T$ $S S X$ transcript is a useful adjunct to the morphologic diagnosis of synovial sarcomas, particularly when minimal biopsy specimens are presented to the pathologist. Our goal was to establish a rapid, sensitive and specific assay for the detection of $S Y T$ $S S X$ transcripts, from fresh or fixed tissue specimens, that can be routinely performed in a clinical laboratory. We have developed an assay combining one step RT-multiplex PCR with capillary electrophoresis to simultaneously detect SYT-SSX fusions involving any $S S X$ gene family member and genotype those involving the $S S X 1$ or $S S X 2$ genes.

\section{Materials and methods}

\section{Specimen Selection}

Formalin-fixed, paraffin-embedded tissue blocks from 32 cases of previously diagnosed soft tissue tumors were retrieved from the files of the University of Michigan Department of Pathology (22 synovial sarcomas, nine malignant peripheral nerve sheath tumors, one epithelioid sarcoma). Diagnoses were made based upon histomorphology and available ancillary studies, which were reviewed by two of the authors (DRL and RER).

\section{RNA Preparation}

A Leitz 1512 rotary microtome was used to cut two $20 \mu \mathrm{m}$ sections from each tumor block, with a new blade being used for each block. The sections were deparaffinized with xylene/ethanol, and the tissue digested overnight with proteinase $\mathrm{K}$. RNA was extracted with Trizol (Invitrogen, Carlsbad, CA, USA) and precipitated with isopropanol essentially as described. ${ }^{18}$ The extracted RNA was resuspended in DEPC-treated deionized water, quantitated spectrophotometrically, and stored at $-70^{\circ} \mathrm{C}$ until use.

\section{Multiplex RT-PCR and Capillary Electrophoresis}

Genomic sequences, including intron-exon boundaries, for all genes and gene products analyzed were obtained from the public database of the National Center for Biotechnology Information. Oligonucleotide primers for use in multiplex PCR were designed using the software programs Primer Express v2.0 (Applied Biosystems, Foster City, CA, USA) and Vector NTI Advance (Informax/Invitrogen). Sequences of all primers used in these studies are shown in Table 1. Fluorochrome-labeled and unlabeled primers were purchased from Applied Biosystems or Integrated DNA Technologies (Coralville, IA, USA). All assays were performed in a total volume of $50 \mu$ l using the GeneAmp ${ }^{\circledR}$ Gold RNA PCR Reagent Kit (Applied Biosystems). For each multiplex assay, $0.1-1.0 \mu \mathrm{g}$ of total RNA was combined with random hexamers and all labeled and unlabeled primers: forward and reverse GAPD specific primers were used at $75 \mathrm{nM}$ final concentration, while the $S Y T$ exon 10 labeled primer was used at $150 \mathrm{nM}$ and unlabeled $S S X$ primers at $200 \mathrm{nM}$. Thermal cycling was carried out in a GeneAmp ${ }^{\mathbb{B}}$ PCR System 9700 instrument (Applied Biosystems) as follows: $42^{\circ} \mathrm{C}$ for $12 \mathrm{~min}, 95^{\circ} \mathrm{C}$ for $10 \mathrm{~min}$, then 43 cycles of $95^{\circ} \mathrm{C}$ for $20 \mathrm{~s}, 58^{\circ} \mathrm{C}$ for $30 \mathrm{~s}, 72^{\circ} \mathrm{C}$ for $1 \mathrm{~min}$. Following PCR amplification, $1 \mu \mathrm{l}$ of each sample was analyzed by capillary electrophoresis on an ABI PRISM ${ }^{\mathbb{R}} 3100$ Genetic Analyzer (Applied Biosystems) using POP-4 ${ }^{\mathrm{TM}}$ polymer and a $36 \mathrm{~cm}$ capillary array. The GeneScan ${ }^{\mathrm{TM}} 500 \mathrm{LIZ}^{\mathrm{TM}}$ Size Standard (Applied Biosystems) was used as internal size standards. Fragment analysis was performed using GeneMapper ${ }^{\circledR}$ ID Software v3.1 (Applied Biosystems).

\section{DNA Sequencing}

PCR amplicons from representative chimeric transcript-positive tumor samples were purified from low-melting temperature agarose gels and ligated

Table 1 Multiplex PCR and sequencing primers

\begin{tabular}{|c|c|}
\hline \\
\hline \multicolumn{2}{|r|}{ 5'-NED-GGAAGGTGAAGGTCGGAGTCAA } \\
\hline \multicolumn{2}{|r|}{ 5'-GACGGTGCCATGGAATTTGC } \\
\hline \multicolumn{2}{|l|}{ SYT-SSX assay } \\
\hline SYT exon 10 & $\begin{array}{l}5^{\prime} \text {-6FAM-AGGTCAGCAGTATGGAGGATATA } \\
\text { GACC }\end{array}$ \\
\hline SSX common & 5'-GCTGGCTTCTTGGGCATGAT \\
\hline SSX1 & 5'-GGCCAGATGCTTCTGACACTC \\
\hline$S S X 2$ & 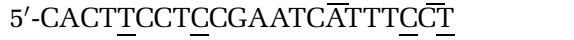 \\
\hline $\begin{array}{l}S S X \text { common } \\
\text { primer for } \\
\text { transcript } \\
\text { sequence } \\
\text { verification }\end{array}$ & 5'-TTTCCCATCGTTTTGTGGGCCAGATGC \\
\hline
\end{tabular}

6FAM, 6 carboxy-fluorescein tag; NED, Applied Biosystems proprietary yellow fluorochrome tag. Bases which are unique to either the SSX1 or SSX2 gene and confer genotype specificity are underlined. 
into the $\mathrm{pCR}^{\circledR} 4$-TOPO ${ }^{\circledR}$ vector using the TOPO TA Cloning Kit for Sequencing (Invitrogen). Ligation products were used to transform chemically competent TOP10 cells (Invitrogen). Colonies were screened for the presence of inserts by PCR, and then grown overnight in broth culture. Plasmid DNA was purified using the Wizard ${ }^{\mathbb{R}}$ Plus Minipreps DNA Purification System (Promega, Madison, WI, USA), then subjected to cycle sequencing in both the forward and reverse directions using the $\mathrm{ABI}$ PRISM $^{\mathbb{R}}$ BigDye $^{\mathrm{TM}}$ Terminator v3.0 Cycle Sequencing kit (Applied Biosystems). Sequencing reactions were analyzed on an ABI PRISM ${ }^{\circledR} 3100$ Genetic Analyzer using $\mathrm{POP}-6^{\mathrm{TM}}$ polymer and a $50 \mathrm{~cm}$ capillary array.

\section{Results}

For detection of the SYT-SSX chimeric transcripts, a one step reverse transcription multiplex PCR assay was designed. Following reverse transcription of RNA using random hexamers, the cDNA is subjected to multiplex PCR amplification using one set of primers specific for $G A P D$ transcripts and a second set of primers specific for SYT-SSX transcripts. The $S Y T-S S X$ transcript specific primer set is composed of one sense primer, annealing to a sequence in exon 10 of the $S Y T$ gene and three antisense primers, the first specific for a sequence common to exon 5 of all members of the $S S X$ gene family, the second specific for a sequence unique to exon 5 of the $S S X 1$ gene, and the third specific to a sequence in exon 5 of the SSX2 gene (see Figure 1). The sense primer of each set is differentially labeled with a fluorochrome, allowing specific detection and sizing of the resulting amplicons by capillary electrophoresis.

Using these primers, as illustrated in Figure 1, amplification of cDNA generated from either an $S Y T-S S X 1$ or and SYT-SSX2 transcript results in the production of two amplicons: one amplicon is identical in size (102 bp) when produced from either type of transcript, whereas the second amplicon differs in size between an SYT-SSX1 transcript (146 bp) or an SYT-SSX2 transcript (130 bp). In the rare case of an SYT-SSX4 transcript, only the $102 \mathrm{bp}$ amplicon would be produced. Within the same reaction, a slightly larger (176 bp) amplicon is also produced from GAPD transcripts. Representative assay results from both an $S Y T-S S X 1$ and an $S Y T-S S X 2$ positive tumor specimen are shown in Figure 2.

The clinical specificity of the assay was evaluated by analyzing RNA extracted from a panel of formalin-fixed, paraffin-embedded tumor specimens. All cases had been diagnosed prior to this study based upon histology and the use of immuno-
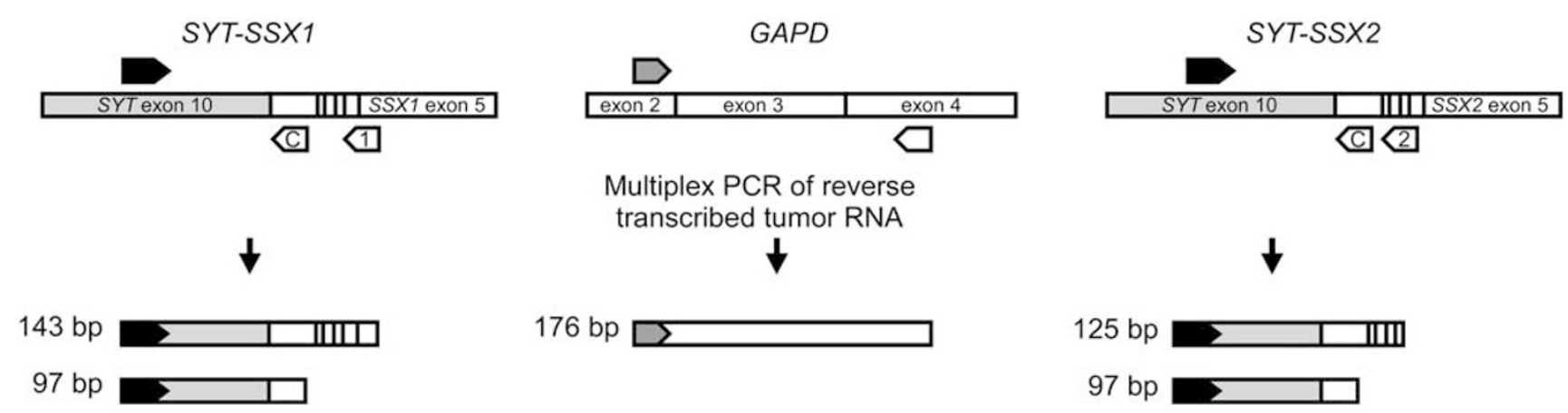

Multiplex PCR of reverse transcribed tumor RNA
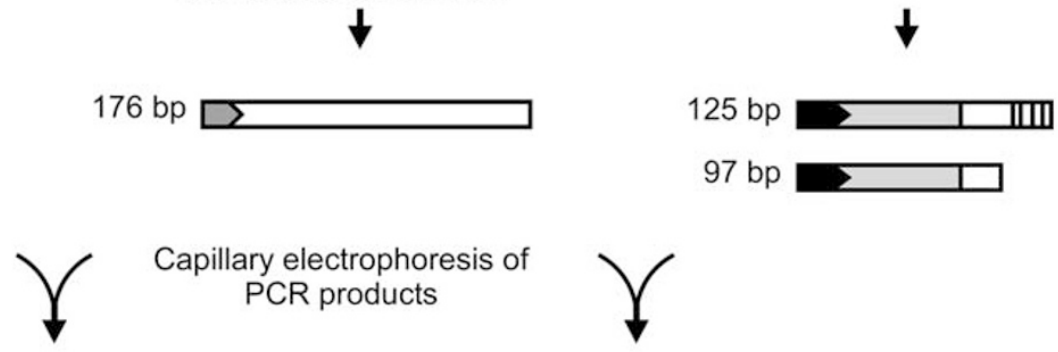

Capillary electrophoresis of PCR products
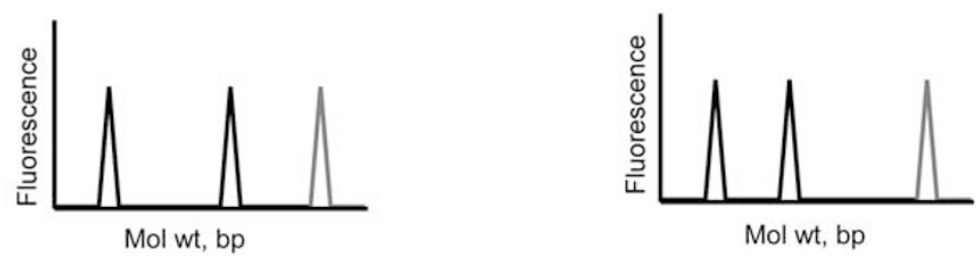

Figure 1 Schematic diagram of RT-multiplex PCR for detection and genotypic characterization of SYT-SSX transcripts, depicting relative locations of primers, PCR amplicon sizes, and expected capillary electrophoresis results from tumors harboring either $S Y T$-SSX1 or $S Y T$ SSX2 transcripts. RNA extracted from FFPE tissue blocks is combined with all RT-PCR reagents in a single tube. A $176 \mathrm{bp}$ NED-labeled amplicon is produced from GAPD transcripts and 6-FAM-labeled amplicons are produced from the SYT-SSX fusion transcripts, one (102 bp) common to $S Y T$ fused to any $S S X$ gene, and a second unique to either SYT-SSX1 (146bp) or SYT-SSX2 (130 bp) transcripts. Products are analyzed by capillary electrophoresis and genotype is assigned based on amplicon sizes. Relative primer locations are depicted by chevrons, $\mathrm{C}$ indicates a common priming site, 1 and 2 are unique sites. Locations of nucleotides, which differ between exon 5 of SSX1 and SSX2 are shown by vertical lines. Labels on the $5^{\prime}$ ends of primers and amplicons are represented as black (6-FAM) or gray (NED). 
a

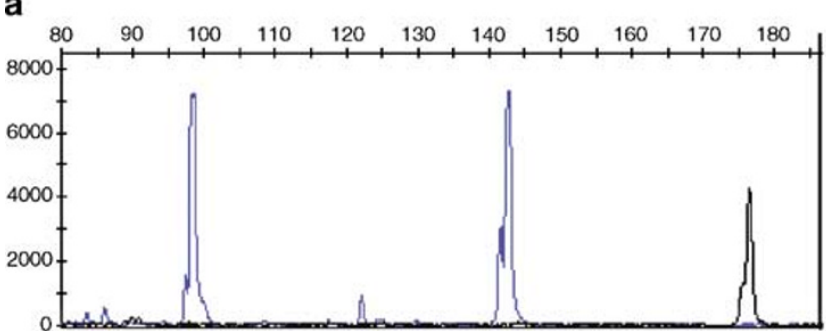

b

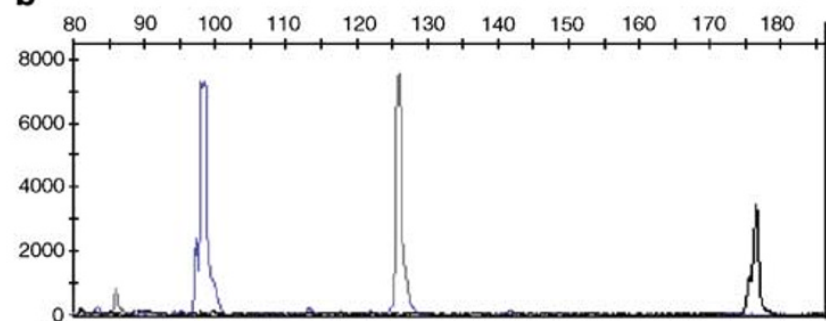

Figure 2 Capillary electrophoresis of RT-multiplex PCR assay products. (a) Results from an SYT-SSX1 positive tumor specimen, while results from an SYT-SSX2 positive specimen are shown in (b). Blue peaks represent SYT-SSX amplicons labeled with 6-FAM, black peaks represent GAPD amplicons labeled with NED. The scale at the top of each electropherogram indicates the amplicon size, in base pairs. The 6-FAM labeled products routinely appear $4 \mathrm{bp}$ smaller than their actual size, eg, the $102 \mathrm{bp} S Y T-S S X$ common amplicon runs at $98 \mathrm{bp}$, while the 130 and $146 \mathrm{bp}$ amplicons run at 126 and $142 \mathrm{bp}$, respectively.

Table 2 Patient cases, tumor location, diagnosis, transcript findings

\begin{tabular}{|c|c|c|c|c|c|}
\hline \multirow[t]{2}{*}{ Case no. } & \multirow[t]{2}{*}{ Age/Sex } & \multirow[t]{2}{*}{ Location } & \multirow[t]{2}{*}{ Diagnosis } & \multicolumn{2}{|c|}{ Assay results } \\
\hline & & & & $G A P D$ & SYT-SSX \\
\hline SS1 & $37 \mathrm{M}$ & Lung & SS, Biphasic & Pos & $S Y T-S S X 1$ \\
\hline SS2 & $19 \mathrm{M}$ & Ankle & SS, Monophasic & $\mathrm{Neg}$ & None \\
\hline SS3 & $72 \mathrm{M}$ & Thigh & SS, Monophasic & Pos & $S Y T-S S X 1$ \\
\hline SS4 & $24 \mathrm{~F}$ & Finger & SS, NOS & Neg & None \\
\hline SS5 & $20 \mathrm{~F}$ & Ankle & SS, Monophasic & Pos & $S Y T-S S X 2$ \\
\hline SS6 & $31 \mathrm{~F}$ & Leg & SS, Monophasic & Pos & $S Y T-S S X 1$ \\
\hline SS7 & $7 \mathrm{~F}$ & Thigh & SS, Monophasic & Neg & None \\
\hline SS8 & $47 \mathrm{M}$ & Knee & SS, Biphasic & Pos & SYT-SSX1 \\
\hline SS9 & $71 \mathrm{M}$ & Thigh & SS, Monophasic & Pos & SYT-SSX1 \\
\hline SS10 & $15 \mathrm{M}$ & Thigh & SS, Biphasic & Pos & SYT-SSX1 \\
\hline SS11 & $26 \mathrm{~F}$ & Hand & SS, Monophasic & $\mathrm{Neg}$ & None \\
\hline SS12 & $52 \mathrm{M}$ & Scrotum & SS, Biphasic & Pos & SYT-SSX1 \\
\hline SS13 & $53 \mathrm{M}$ & Thigh & SS, Biphasic & Pos & $S Y T-S S X 1$ \\
\hline SS14 & $36 \mathrm{~F}$ & Lung & SS, Biphasic & Pos & SYT-SSX2 \\
\hline SS15 & $58 \mathrm{M}$ & Lymph node & SS, Biphasic & Pos & $S Y T-S S X 1$ \\
\hline SS16 & $44 \mathrm{M}$ & Thigh & SS, Biphasic & Pos & $S Y T-S S X 1$ \\
\hline SS17 & $18 \mathrm{M}$ & Foot & SS, Monophasic & Neg & None \\
\hline SS18 & $18 \mathrm{~F}$ & Face & SS, biphasic & Pos & SYT-SSX1 \\
\hline SS19 & $21 \mathrm{~F}$ & Thigh & SS, Monophasic & Pos & SYT-SSX2 \\
\hline SS20 & $39 \mathrm{M}$ & Shoulder & SS, Biphasic & Pos & $S Y T-S S X 1$ \\
\hline SS21 & $59 \mathrm{M}$ & Lung & SS, Monophasic & Pos & $S Y T-S S X 2$ \\
\hline SS22 & $11 \mathrm{M}$ & Neck & SS, Monophasic & Pos & $S Y T-S S X 2$ \\
\hline $\mathrm{C} 1$ & $44 \mathrm{M}$ & Parotid gland & MPNST & Pos & None \\
\hline $\mathrm{C} 2$ & $26 \mathrm{~F}$ & Calf & MPNST & Pos & None \\
\hline C3 & $41 \mathrm{~F}$ & Chest wall & MPNST & Pos & None \\
\hline $\mathrm{C} 4$ & $35 \mathrm{M}$ & Flank & MPNST & Pos & None \\
\hline C5 & $4 \mathrm{M}$ & Brachial plexus & MPNST & Pos & None \\
\hline C6 & $52 \mathrm{~F}$ & Neck & MPNST & Pos & None \\
\hline C7 & $52 \mathrm{~F}$ & Thigh & MPNST & Pos & None \\
\hline C8 & $9 \mathrm{M}$ & Lumbar fascia & MPNST & Pos & None \\
\hline C9 & $28 \mathrm{M}$ & Buttock & MPNST & Pos & None \\
\hline C10 & $12 \mathrm{M}$ & Hand & Epithelioid sarcoma & Pos & None \\
\hline
\end{tabular}

SS, synovial sarcoma; NOS, not otherwise specified; MPNST, malignant peripheral nerve sheath tumor.

histochemical markers, including antibodies to cytokeratin filaments, epithelial membrane antigen, and S100 protein, among others. Of 22 synovial sarcoma specimens, 11 were monophasic, 10 were biphasic, and for one the histomorphology was uncertain due to a small sample size and loss of architectural integrity.

The results of the RT-multiplex PCR assay and the histomorphological characteristics of the corre- sponding tumor specimens are presented in Table 2. For 17/22 synovial sarcoma specimens, both a GAPD amplicon and SYT-SSX amplicons were produced. In all, 12 of 17 genotyped as SYT-SSX1 (nine biphasic, three monophasic), while $5 / 17$ genotyped as $S Y T$ SSX2 (one biphasic, four monophasic). For the remaining 5/22 synovial sarcoma specimens, neither a GAPD amplicon nor any SYT-SSX amplicons were produced, suggesting either the lack of intact RNA or 
a

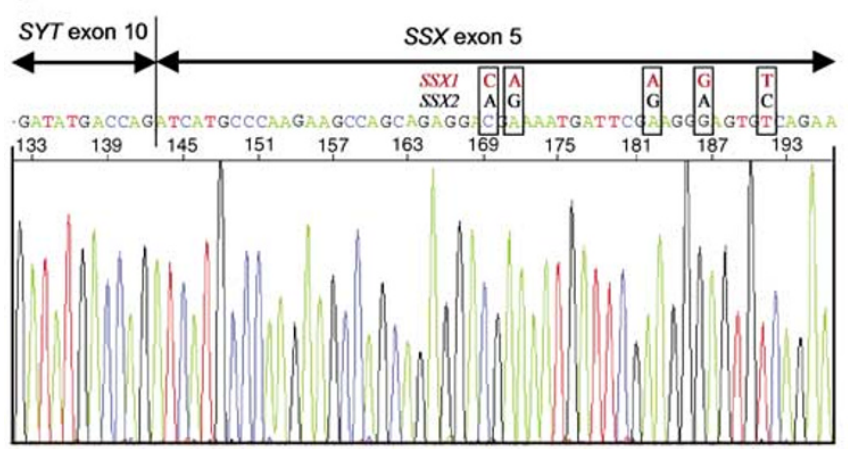

b

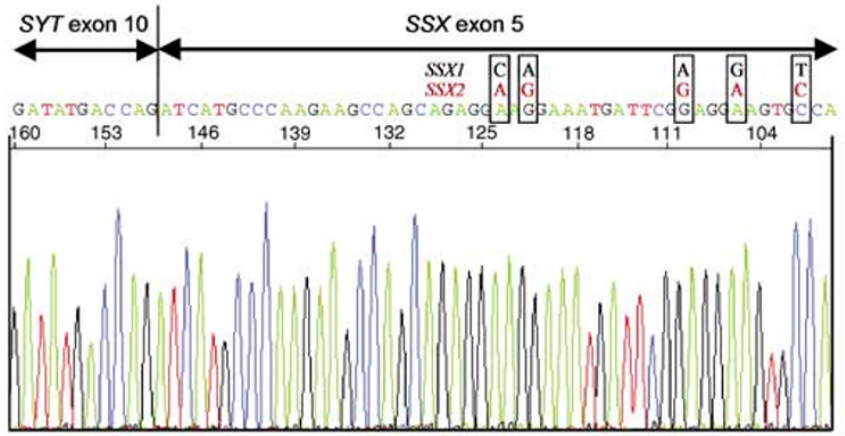

Figure 3 Sequence analysis of cDNA from SYT-SSX transcripts. RNA from synovial sarcoma specimens was used to generate RT-PCR amplicons using the SYT exon 10 sense primer in combination with an antisense $S S X$ exon 5 primer annealing to a region downstream of the genotype specific $S S X$ sequences. The amplicons were ligated into a plasmid vector and sequenced in both the forward and reverse directions. (a) Results from an SYT-SSX1 tumor; (b) results from an SYT-SSX2 tumor. The fusion junctions of the $S Y T$ and $S S X$ exons are indicated. Nucleotides which define the $S Y T-S S X$ genotype are indicated above each sequence and are enclosed in boxes.

the presence of a PCR inhibitor. Re-analysis of a diluted RNA specimen failed to produce a positive result in all five cases (data not shown). No SYT-SSX amplicons were produced from RNA extracted from 9/ 9 malignant nerve sheath tumors or $1 / 1$ epithelioid sarcoma; however, each of these specimens did yield a GAPD amplicon.

In order to confirm the genotype specificity of the assay, RNA from an SYT-SSX1-positive tumor and an SYT-SSX2-positive tumor was reverse transcribed and amplified using an unlabeled version of the SYT specific primer in conjunction with an antisense primer located in a sequence common to the SSX genes, downstream of the sequences targeted by the genotype-specific primers. The amplicons were ligated into the pCR4-TOPO plasmid and the resulting constructs sequenced in the forward and reverse directions. As shown in Figure 3 , in each case examined the genotype predicted by the RT-multiplex PCR assay was confirmed by sequence analysis.

\section{Discussion}

We have developed an assay that utilizes one-step RT-multiplex PCR coupled with capillary electrophoresis to detect and genotype the SYT-SSX chimeric transcripts that characterize synovial sarcomas. In our analysis of 32 previously diagnosed soft tissue tumor specimens, a positive result was obtained with this assay from 17/22 formalinfixed synovial sarcoma specimens (77\% sensitivity) while 9/9 malignant peripheral nerve sheath tumors and $1 / 1$ epithelioid sarcoma were negative $(100 \%$ specificity).

The failure to produce an $S Y T-S S X$ amplicon from five of the 22 synovial sarcoma cases could result from poor RNA quality, an atypical fusion transcript, or the absence of a translocation in those particular tumor specimens. Significantly, there was a $100 \%$ correlation between SYT-SSX negativity and the apparent absence of intact RNA in the extracted specimens, as demonstrated by the inability to produce a GAPD amplicon from these same specimens. This finding might reflect differences in fixation time or in the age of the specimens at the time of RNA extraction, as both of these factors have been shown to affect the quality of extractable nucleic acids. ${ }^{19}$ Although the fixation time used for each of these specimens is not known, we found no definitive correlation between the age of the specimen and the presence of intact RNA (data not shown).

Rare cases of synovial sarcoma in which the $S Y T$ gene is fused to the $S S X 4$ gene have been reported;,20 however, our assay should detect transcripts from this type of fusion as well, by virtue of its use of a primer site common to all $S S X$ gene family members (ie, 102 bp amplicon, Figure 1) in addition to the $S S X 1$ and $S S X 2$ gene-specific priming sites. In any event, a $77 \%$ sensitivity is not unlike that which has been previously reported for RT-PCR-based studies on fixed tissue specimens. ${ }^{21}$

As increasing emphasis is placed upon minimally invasive biopsy strategies, molecular approaches to the diagnosis of soft tissue tumors are frequently required in routine practice. As a result of this, it is desirable for a clinical laboratory to have available an assay which can be utilized on fresh or fixed tissue specimens, has a rapid turn around time, and provides results which are rapidly and accurately interpretable. A variety of approaches to the detection of chimeric fusion genes or their transcripts can be utilized, including conventional cytogenetics, fluorescence in situ hybridization (FISH) and several variations of RT-PCR. ${ }^{22-27}$ The RT-multiplex PCR/capillary electrophoresis assay described here was designed to produce small ( $<150 \mathrm{bp}$ ), genotypespecific amplicons from $S Y T-S S X$ fusion transcripts as well as a slightly larger amplicon from the normal $G A P D$ transcript, making it well suited for use on RNA extracted from fixed tissue specimens. Through the use of $S S X$ genotype-specific and 
non-specific primers and a multiplex design, the assay has the ability to detect fusion transcripts involving any $S S X$ gene, and simultaneously genotype the two most common forms. The reliability of this design for correctly genotyping tumorderived transcripts was confirmed by direct sequencing of PCR products. The single tube format of our assay simplifies interpretation, in that the presence or absence of a $G A P D$ amplicon helps to distinguish a true negative result (ie, GAPD amplicon present without fusion gene amplicon) from a false negative result due to PCR inhibitors or poor RNA quality (neither GAPD amplicon nor fusion gene amplicon present). Although little can be done to circumvent poor RNA quality, the effect of a PCR inhibitor, once recognized, can frequently be overcome by reanalysis of a diluted specimen. Finally, because the GAPD gene may be expressed at a level above that of the fusion gene in some cases, the sensitivity of this assay was intentionally biased to favor amplification of the fusion gene transcript by adjusting the ratio of primer concentrations. Sample dilution experiments (data not shown) demonstrate that, in all cases examined, GAPD amplicons become undetectable prior to the point at which fusion gene amplicons become undetectable. This reduces the likelihood of a false negative interpretation of the assay (ie, GAPD amplicon present but fusion gene amplicon present at a level below the detection limit of the assay).

The detection of specific chimeric fusion gene transcripts as an adjunct to the histological diagnosis of soft tissue tumors, such as Ewing's sarcoma, desmoplastic small round cell tumor, alveolar rhabdomyosarcoma, and synovial sarcoma has become an important tool for the pathologist. Assays for these markers can provide an increased level of confidence in the accurate diagnosis of soft tissue tumors, particularly for those cases where biopsy specimens are small or in which the morphologic features present may be seen in more than one tumor type. The utility of RT-PCR-based assays for this purpose is well recognized..$^{28,29}$ The RT-multiplex PCR/capillary electrophoresis assay described here is easily performed in a clinical molecular diagnostics laboratory and provides reliable results from formalin-fixed tissue specimens. The assay results are readily interpreted and, through the use of an internal amplification control, questions concerning RNA integrity or PCR inhibition frequently encountered with fixed tissue specimens are minimized.

\section{References}

1 Lewis J, Antonescu C, Leung D, et al. Synovial sarcoma: a multivariate analysis of prognostic factors in 112 patients with primary localized tumors of the extremity. J Clin Oncol 2000;18:2087-2094.
2 dos Santos N, de Bruijn DRH, Geurts van Kessel A. Molecular mechanisms underlying human synovial sarcoma development. Genes Chromosomes Cancer 2001;30:1-14.

3 Turc-Carel C, Dal Cin P, Limon J, et al. Translocation $\mathrm{X} ; 18$ in synovial sarcoma. Cancer Genet Cytogenet 1986;23:93.

4 Limon J, Dal Cin P, Sandberg AA. Translocations involving the $\mathrm{X}$ chromosome in solid tumors: presentation of two sarcomas with $t(X ; 18)(q 13 ; q 11)$. Cancer Genet Cytogenet 1986;23:87-91.

5 Clark J, Rocques PJ, Crew AJ, et al. Identification of novel genes, SYT and SSX, involved in the $\mathrm{t}(\mathrm{X} ; 18)(\mathrm{p} 11.2 ; \mathrm{q} 11.2)$ translocation found in human synovial sarcoma. Nat Genet 1994;7:502-508.

6 Ladanyi M. Fusions of the SYT and SSX genes in synovial sarcoma. Oncogene 2001;20:5755-5762.

7 Crew AJ, Clark J, Fisher C, et al. Fusion of SYT to two genes, SSX1 and SSX2, encoding proteins with homology to the Kruppel-associated box in human synovial sarcoma. EMBO J 1995;14:2333-2340.

8 de Leeuw B, Balemans $\mathrm{M}$, Olde Weghuis $\mathrm{D}$, et al. Identification of two alternative fusion genes, SYT-SSX1 and SYT-SSX2, in $\mathrm{t}(\mathrm{X} ; 18)(\mathrm{p} 11.2 ; \mathrm{q} 11.2)-$ positive synovial sarcomas. Hum Mol Genet 1995; 4:1097-1099.

9 Skytting B, Nilsson G, Brodin B, et al. A novel fusion gene, SYT-SSX4, in synovial sarcoma. J Natl Cancer Inst 1999;91:974-975.

10 Wei Y, Sun M, Nilsson G, et al. Characteristic sequence motifs located at the genomic breakpoints of the translocation $t(X ; 18)$ in synovial sarcomas. Oncogene 2003;22:2215-2222.

11 Guillou L, Coindre J, Gallagher G, et al. Detection of the synovial sarcoma translocation $t(X ; 18)$ (SYT;SSX) in paraffin-embedded tissues using reverse transcriptase-polymerase chain reaction: a reliable and powerful diagnostic tool for pathologists. A molecular analysis of 221 mesenchymal tumors fixed in different fixatives. Hum Pathol 2001;32:105-112.

12 Hiraga H, Nojima T, Abe S, et al. Diagnosis of synovial sarcoma with the reverse transcriptase-polymerase chain reaction: analyses of 84 soft tissue and bone tumors. Diagn Mol Pathol 1998;7:102-110.

13 van de Rijn M, Barr FG, Collins $\mathrm{MH}$, et al. Absence of SYT-SSX fusion products in soft tissue tumors other than synovial sarcoma. Am J Clin Pathol 1999; 112:43-49.

14 Guillou L, Benhattar J, Bonichon F, et al. Histologic grade, but not SYT-SSX fusion type, is an important prognostic factor in patients with synovial sarcoma: a multicenter, retrospective analysis. J Clin Oncol 2004; 22:4040-4050.

15 Ladanyi M. Correlates of SYT-SSX fusion type in synovial sarcoma: getting more complex but also more interesting? [letter]. J Clin Oncol 2005;23:3638-3639.

16 Ladanyi $\mathrm{M}$, Antonescu CR, Leung $\mathrm{DH}$, et al. Impact of SYT-SSX fusion type on the clinical behavior of synovial sarcoma: a multi-institutional retrospective study of 243 patients. Cancer Res 2002; 62:135-140.

17 Antonescu CR, Kawai A, Leung DH, et al. Strong association of SYT-SSX fusion type and morphologic epithelial differentiation in synovial sarcoma. Diagn Mol Pathol 2000;9:1-8.

18 Krafft A, Duncan B, Bijwaard K, et al. Optimization of the isolation and amplification of RNA from formalin- 
fixed, paraffin-embedded tissue: The Armed Forces Institute of Pathology experience and literature review. Mol Diagn 1997;2:217-230.

19 Srinivasan M, Sedmak D, Jewell S. Effect of fixatives and tissue processing on the content and integrity of nucleic acids. Am J Pathol 2002;161:1961-1971.

20 Mezzelani A, Dagrada GP, Sozzi G, et al. SYT-SSX fusion transcripts and epithelial differentiation in synovial sarcoma. Diagn Mol Pathol 2000;9:234.

21 Hill DA, O’Sullivan MJ, Zhu X, et al. Practical application of molecular genetic testing as an aid to the surgical pathologic diagnosis of sarcomas: a prospective study. Am J Surg Pathol 2002;26:965-977.

22 Bijwaard KE, Fetsch JF, Przygodzki R, et al. Detection of SYT-SSX fusion transcripts in archival synovial sarcomas by real-time reverse transcriptase-polymerase chain reaction. J Mol Diagn 2002;4:59-64.

23 Cummings TJ, Brown NM, Stenzel TT. TaqMan junction probes and the reverse transcriptase polymerase chain reaction: detection of alveolar rhabdomyosarcoma, synovial sarcoma, and desmoplastic small round cell tumor. Ann Clin Lab Sci 2002;32:219-224.

24 Gaffney R, Chakerian A, O’Connell JX, et al. Novel fluorescent ligase detection reaction and flow cyto- metric analysis of SYT-SSX fusions in synovial sarcoma. J Mol Diagn 2003;5:127-135.

25 Hill DA, Riedley SE, Patel AR, et al. Real-time polymerase chain reaction as an aid for the detection of SYT-SSX1 and SYT-SSX2 transcripts in fresh and archival pediatric synovial sarcoma specimens: report of 25 cases from St Jude Children's Research Hospital. Pediatr Dev Pathol 2003;6:24-34.

26 Sandberg AA, Bridge JA. Updates on the cytogenetics and molecular genetics of bone and soft tissue tumors. Synovial sarcoma. Cancer Genet Cytogenet 2002;133:1-23.

27 Surace C, Panagopoulos I, Palsson E, et al. A novel FISH assay for SS18-SSX fusion type in synovial sarcoma. Lab Invest 2004;84:1185-1192.

28 Argani P, Zakowski MF, Klimstra DS, et al. Detection of the SYT-SSX chimeric RNA of synovial sarcoma in paraffin-embedded tissue and its application in problematic cases. Mod Pathol 1998;11:65-71.

29 Willeke F, Mechtersheimer G, Schwarzbach M, et al. Detection of SYT-SSX1/2 fusion transcripts by reverse transcriptase-polymerase chain reaction (RT-PCR) is a valuable diagnostic tool in synovial sarcoma. Eur J Cancer 1998;34:2087-2093. 